\title{
Efeito da adição de argila fundente ilítica em cerâmica vermelha de argilas cauliníticas
}

\section{(Effect of illitic flux clay addition in red ceramic of kaolinitic clays)}

\author{
C. M. F. Vieira, H. F. Sales, S. N. Monteiro \\ Laboratório de Materiais Avançados - LAMAV \\ Universidade Estadual do Norte Fluminense - UENF \\ Av. Alberto Lamego, 2000, Campos dos Goytacazes, RJ 28013-600 \\ vieira@uenf.br
}

\begin{abstract}
Resumo
A incorporação de uma argila ilítica com características fundentes em massa de cerâmica vermelha composta de argilas predominantemente cauliníticas foi avaliada em relação às alterações produzidas na microestrutura e nas propriedades físicas e mecânicas. As matériasprimas foram caracterizadas através de ensaios de difração de raios X, composição química, distribuição de tamanho de partículas e plasticidade. Foram preparadas composições, com percentuais de argila fundente de $0,10,20$ e $30 \%$ em peso, usadas na fabricação de corpos-de-prova por prensagem uniaxial para queima em temperaturas variando de $850{ }^{\circ} \mathrm{C}$ a $1100{ }^{\circ} \mathrm{C}$. As propriedades tecnológicas avaliadas foram: absorção de água, retração linear e tensão de ruptura à flexão (3 pontos). Análise microestrutural foi realizada por porosimetria de mercúrio e microscopia eletrônica de varredura. Os resultados indicaram que a adição de argila fundente ilítica à massa cerâmica contribuiu para redução da porosidade e, conseqüentemente, melhoria nas propriedades tecnológicas avaliadas.
\end{abstract}

Palavras-chave: Argila, caulinita, fundente, ilita, microestrutura.

Abstract

The incorporation of a illitic clay with flux characteristics into a red ceramic body of clays predominantly kaolinitic was evaluated with respect to the changes produced in the microstructure and mechanical and physical properties. The raw materials were characterized through X-ray diffraction, chemical composition, particle size distribution and plasticity tests. Compositions were prepared with 0,10 , 20 and $30 \mathrm{wt} \%$ flux clay. Specimens were prepared by uniaxial pressing and fired at temperatures varying from $850^{\circ} \mathrm{C}$ to $1100^{\circ} \mathrm{C}$. The evaluated technological properties were: water absorption, linear shrinkage and flexural rupture strength (three points). A microstructural analysis was carried out by mercury porosimetry and scanning electron microscopy. The results showed that the illitic flux clay addition into the ceramic body contributed to decrease the porosity and, consequently, to improve the technological properties.

Keywords: Clay, Kaolinite, flux, illite, microstructure.

\section{INTRODUÇÃO}

Massas de cerâmica vermelha usadas nas industrias de Campos dos Goytacazes, região norte do Estado do Rio de Janeiro, caracterizam-se por apresentar um comportamento de queima refratário que, para alguns tipos de produtos como telhas e pisos extrudados, não permite alcançar as propriedades requeridas. Um estudo comparativo das características de uma típica massa cerâmica para telhas do município de Campos dos Goytacazes e massas de reconhecida qualidade provenientes de outras regiões, constatou que a massa de Campos apresenta características significativamente diferentes das demais [1]. Dentre estas características destacam-se um elevado percentual de alumina, baixo percentual de sílica, excessivo conteúdo de minerais argilosos e elevada perda de massa durante a queima, associadas basicamente à predominância caulinítica das argilas locais. Além disso, estas argilas possuem gibsita (hidróxido de alumínio) em sua composição mineralógica $[2,3]$. A gibsita durante a queima sofre uma transformação pseudomórfica em temperaturas em torno de $260{ }^{\circ} \mathrm{C}$, contribuindo também para aumento da refratariedade e perda de massa.

Como alternativas para melhorar as propriedades após queima dos produtos pode-se reformular a massa cerâmica, aumentando o teor de fundentes e/ou a temperatura de queima. Os fundentes atuam na formação de fase líquida que preenche os vazios na microestrutura do material, contribuindo para incrementar a densificação e reduzir a porosidade [4, 5], por meio de um processo comumente chamado de vitrificação. Os fundentes mais utilizados em cerâmicas, sobretudo naquelas para construção civil, são matérias-primas ricas em $\mathrm{Na}_{2} \mathrm{O}$ e $\mathrm{K}_{2} \mathrm{O}$, os quais formam fase líquida por fusão própria ou, em reação com a sílica $\left(\mathrm{SiO}_{2}\right)$, formam eutéticos a partir de temperaturas de aproximadamente $700{ }^{\circ} \mathrm{C}$ [6]. A temperatura de queima, a percentagem e proporção dos óxidos alcalinos, bem como sua procedência mineralógica, são alguns dos fatores determinantes no processo de vitrificação.

Em trabalhos anteriores, ficou constatada a eficiência da 
incorporação de fundentes na redução da porosidade de cerâmica vermelha da região de Campos dos Goytacazes [7, 8]. Entretanto, isto só foi obtido em temperaturas superiores a $1000^{\circ} \mathrm{C}$. Neste caso, a aplicação industrial fica comprometida, pois os fornos das indústrias de Campos dos Goytacazes, na maioria do tipo Hoffmann, não suportam bem tais temperaturas por não possuírem tijolos refratários adequados.

A adição de argila fundente ilítica na composição da massa é uma outra alternativa para a redução da porosidade de cerâmica vermelha de predominância caulinítica. Ela apresenta o seu baixo custo como grande vantagem em comparação com outros tipos de fundentes como filito, granito e fonolito. Entretanto, ainda não se tem conhecimento de depósitos exploráveis deste tipo de material no Estado do Rio de Janeiro, havendo somente comentários sobre a existência de material similar. O levantamento destes dados seria de grande utilidade para as indústrias de cerâmica vermelha e poderia abrir uma boa perspectiva para a fabricação de outros tipos de produtos como os revestimentos prensados.

Neste sentido, este trabalho teve como objetivo avaliar a incorporação de argila fundente ilítica nas propriedades tecnológicas e microestruturas de uma massa de cerâmica vermelha, preparada com argilas cauliníticas, para fabricação de telhas da região de Campos dos Goytacazes.

\section{MATERIAIS E MÉTODOS}

Para realização deste trabalho foram utilizadas como matérias-primas uma argila fundente e uma massa cerâmica industrial utilizada para fabricação de telhas vermelha dos tipos romana/portuguesa. A argila fundente ilítica, proveniente da região de Santa Gertrudes, Estado de S. Paulo, é conhecida como taguá, sendo comumente utilizada em composição de massa para fabricação de revestimentos cerâmicos prensados [9, 10]. Esta argila denominada "mole", extraída do nível superior da jazida, foi fornecida pela empresa Calcáreo Cruzeiro. A massa industrial foi proveniente de indústria localizada no município de Campos dos Goytacazes.

As matérias-primas foram secas em estufa a $110{ }^{\circ} \mathrm{C}$, desagregadas com pilão manual e peneiradas em 40 mesh $(425 \mu \mathrm{m})$ para ensaios de caracterização e preparação das composições.

A caracterização mineralógica por difração de raios X foi feita em amostras em forma de pó em difratômetro SHEIFERT modelo URD 65, operando com radiação $\mathrm{Cu}-\mathrm{k}_{\alpha}$ e $2 \theta$ variando de $5^{\circ}$ a $65^{\circ}$. A composição química das matérias-primas foi obtida por espectrometria de fluorescência de raios X. A distribuição de tamanho de partículas foi feita por peneiramento via úmida e sedimentação. A plasticidade das matérias-primas foi obtida através da determinação dos limites de Atterberg, de acordo com as normas NBR 7180-84 e NBR 6459-84 [11, 12].

Foram preparadas quatro composições com os seguintes percentuais de argila fundente: $0,10,20$, e $30 \%$ em peso, conforme mostra a Tabela I. Nesta tabela a sigla MI corresponde à massa industrial e AF, à argila fundente.

Corpos-de-prova na forma de paralelepípedos retangulares $\left(11,43 \times 2,54 \times 10,0 \mathrm{~cm}^{3}\right)$ foram fabricados por prensagem uniaxial em matriz de aço a $20 \mathrm{MPa}$ com umidade de $8 \%$,
Tabela I - Composições estudadas (\% em peso).

[Table I - Studied compositions (wt. \%).]

\begin{tabular}{lcc}
\hline & \multicolumn{2}{c}{ Matérias-primas } \\
\cline { 2 - 3 } Composições & & \\
\cline { 2 - 3 } & Massa industrial & Argila fundente \\
\hline MI & 100 & - \\
\hline MI10AF & 90 & 10 \\
\hline MI20AF & 80 & 20 \\
\hline MI30AF & 70 & 30 \\
\hline
\end{tabular}

sendo em seguida secos em estufa a $110^{\circ} \mathrm{C}$ até massa constante. A queima foi realizada em forno de laboratório tipo mufla em temperaturas variando de $850^{\circ} \mathrm{C}$ a $1100^{\circ} \mathrm{C}$ com intervalos de $50{ }^{\circ} \mathrm{C}$. Utilizou-se uma taxa de aquecimento de $5^{\circ} \mathrm{C} / \mathrm{min}$ e $3 \mathrm{~h}$ de tempo de permanência nas temperaturas de patamar. $\mathrm{O}$ resfriamento foi obtido por convecção natural, desligando-se o forno. Propriedades tecnológicas de queima relacionadas com absorção de água, retração linear e tensão de ruptura à flexão ( 3 pontos) foram determinadas por meio de ensaios padronizados $[13,14]$.

A análise dos vazios microestruturais foi feita por meio de ensaios de porosimetria de mercúrio em porosímetro Quantachrome Autoscan 33, com ângulo de contato $140^{\circ}$. A observação da região de fratura de amostras queimadas foi feita por microscopia eletrônica de varredura em um microscópio ZEISS modelo DSM 962.

\section{RESULTADOS E DISCUSSÃO}

\section{Caracterização das matérias-primas}

A Fig. 1 apresenta os difratogramas de raios $\mathrm{X}$ da massa industrial e da argila fundente. Observa-se que na massa industrial os picos de maior intensidade estão associados à caulinita. Observa-se também picos característicos do quartzo, mineral micáceo (mica muscovita) e gibsita (hidróxido de alumínio). Já a argila fundente apresenta picos predominantes do quartzo, seguidos de feldspatos potássico e pagioclásios, mineral micáceo (ilita/mica muscovita) e hematita.

De acordo com a Tabela II, a massa industrial apresenta composição química típica de argila caulinítica, com baixo percentual de óxidos fundentes e elevado teor de $\mathrm{Al}_{2} \mathrm{O}_{3}$. O baixo percentual de $\mathrm{SiO}_{2}$ e a elevada perda ao fogo estão associados a um maior percentual de mineral argiloso ou "fração argila". Por sua vez, a argila fundente apresenta elevado percentual de óxidos alcalinos, sobretudo $\mathrm{K}_{2} \mathrm{O}$, e baixo percentual de $\mathrm{Al}_{2} \mathrm{O}_{3}$. Nota-se também um elevado teor de $\mathrm{SiO}_{2}$ e baixa perda ao fogo que estão relacionados com um maior teor de fração silte/areia em sua composição mineralógica, bem como ao próprio predomínio da estrutura ilítica sobre a caulinítica. Observa-se, adicionalmente, que ambas matériasprimas apresentam teor de $\mathrm{MgO}$ superior a $1 \%$ em massa. $\mathrm{O}$ 


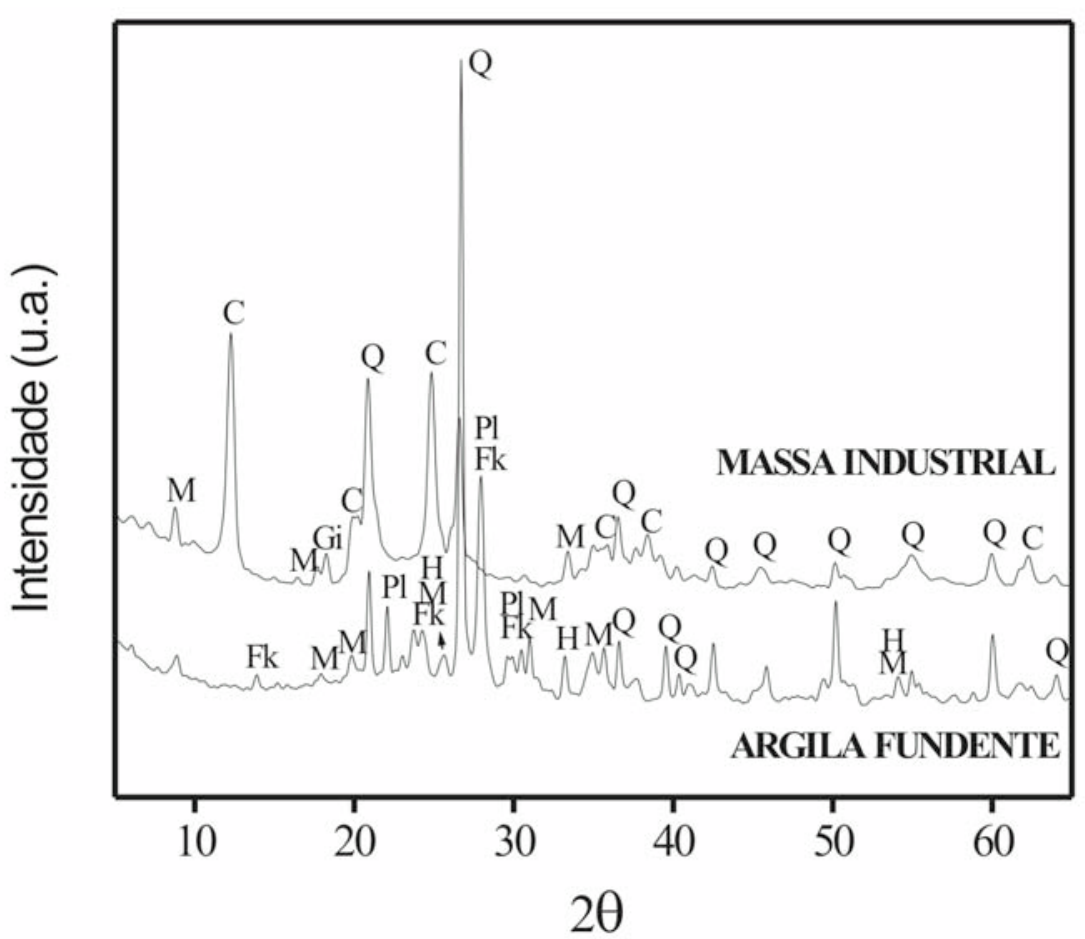

Figura 1: Difratogramas de raios $\mathrm{X}$ das matérias-primas. $\mathbf{C}=$ Caulinita; $\mathbf{F k}=$ Feldspato potássico; $\mathbf{G i}=$ Gibsita; $\mathbf{H}=$ Hematita; $\mathbf{M}=$ Mineral micáceo; $\mathbf{P I}=$ Feldspato plagioclásio; $\mathbf{Q}=$ Quartzo.

[Figure 1: X-ray diffraction patterns of the raw materials. $\boldsymbol{C}=$ Kaolinite; $\boldsymbol{F} \boldsymbol{k}=$ Potash feldspar; $\boldsymbol{G i}=$ Gibbsite; $\boldsymbol{H}=$ Hematite; $\boldsymbol{M}=$ Micaceous mineral; $\boldsymbol{P l}=$ Plagioclase feldspars; $\boldsymbol{Q}=$ Quartz.]

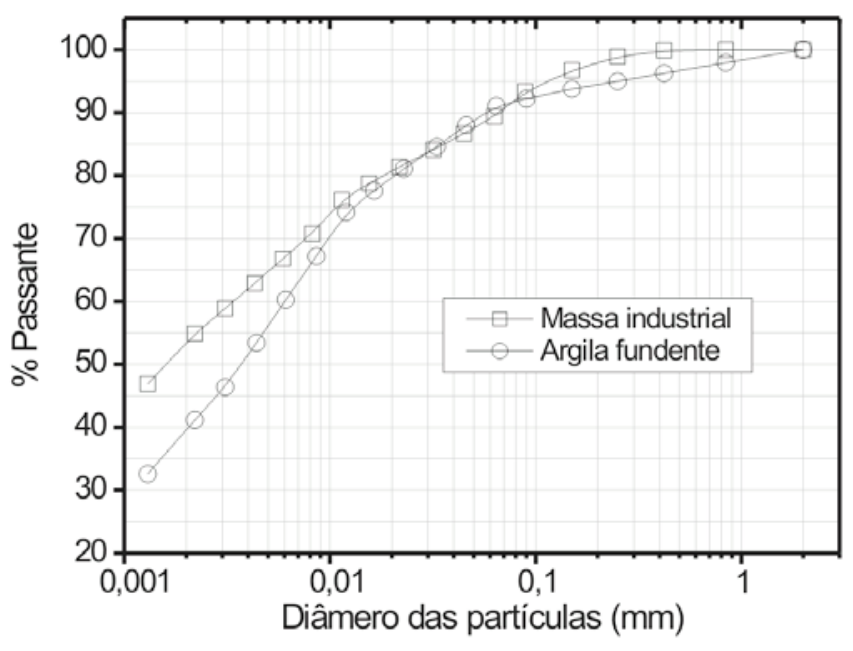

Figura 2: Distribuição de tamanho de partículas das matérias-primas. [Figure 2: Particle size distribution of the raw materials.]
$\mathrm{MgO}$ pode estar associado a traços de cloritas e vermiculitas, não identificáveis nos difratogramas de raios $\mathrm{X}$, ou então presente na estrutura cristalina dos minerais micáceos. Por fim, observa-se que ambas matérias-primas apresentam elevado teor de $\mathrm{Fe}_{2} \mathrm{O}_{3}$, responsável pela coloração avermelhada após queima.

A Fig. 2 mostra a distribuição de tamanho de partículas das matérias-primas. Vale aqui constatar que a massa industrial apresenta maior percentual de minerais argilosos ou "fração argila" que a argila fundente. Os minerais argilosos são comumente associados a partículas com diâmetro esférico equivalente $<2 \mu \mathrm{m}$. Neste caso, a massa industrial e a argila fundente apresentam "fração argila" de 53 e $34 \%$ em peso, respectivamente. Já relativamente ao teor de areia, $>20 \mu \mathrm{m}$, as matérias-primas apresentam percentuais similares com $11 \%$ para a massa industrial e $9 \%$ em massa para a argila fundente. Isto mostra que a argila fundente é granulometricamente formada com predomínio de tamanho de partículas (d) associadas ao silte, $2 \mu \mathrm{m}<\mathrm{d}<20 \mu \mathrm{m}$.

Tabela II - Composição química das matérias-primas (\% em peso).

[Table II - Chemical composition of the raw materials (wt. \%).]

\begin{tabular}{|c|c|c|c|c|c|c|c|c|c|}
\hline \multicolumn{10}{|c|}{ Determinações } \\
\hline Matérias-primas & $\mathrm{SiO}_{2}$ & $\mathrm{Al}_{2} \mathrm{O}_{3}$ & $\mathrm{Fe}_{2} \mathrm{O}_{3}$ & $\mathrm{TiO}_{2}$ & $\mathrm{CaO}$ & MgO & $\mathbf{K}_{2} \mathbf{O}$ & $\mathrm{Na}_{2} \mathrm{O}$ & PF \\
\hline Massa industrial & 42,49 & 29,24 & 9,21 & 1,44 & 0,24 & 1,10 & 1,41 & 0,51 & 14,08 \\
\hline Argila fundente & 67,34 & 15,10 & 0,63 & 0,63 & 0,41 & 1,48 & 3,61 & 0,59 & 5,02 \\
\hline
\end{tabular}


Tabela III - Plasticidade das matérias-primas. [Table III - Plasticity of the raw materials.]

\begin{tabular}{lcc}
\hline & \multicolumn{2}{c}{ Matérias-primas } \\
Limites de & Massa & Argila \\
Atterberg & industrial & fundente \\
\hline LP & 29 & 30 \\
\hline LL & 64 & 55 \\
\hline IP & 35 & 25 \\
\hline
\end{tabular}

A Tabela III apresenta a plasticidade das matérias-primas, determinada por meio dos limites de Atterberg. Observa-se que tanto a massa industrial quanto a argila fundente apresentam limites de plasticidade (LP) muito próximos. O LP indica a quantidade de água necessária para alcançar uma consistência plástica e, conseqüentemente, a capacidade para moldagem por extrusão. Apesar do menor teor de minerais argilosos (minerais que desenvolvem plasticidade) da argila fundente, seu caráter ilítico contribuiu para este resultado. A ilita apresenta plasticidade mais elevada que a caulinita [15]. Além disso, na fração granulométrica do silte, pode haver também partículas de minerais argilosos e um certo desenvolvimento de plasticidade. Com relação ao limite de liquidez (LL), a massa cerâmica apresenta valor consideravelmente mais elevado que a argila fundente. O LL indica a quantidade de água acima da qual uma matéria-prima argilosa não apresenta mais uma consistência plástica e passa a se comportar como líquido [16]. Neste caso, o maior teor de mineral argiloso da massa industrial foi fundamental para o seu elevado teor de LL. Por fim, o índice de plasticidade (IP) indica a faixa de consistência plástica de uma matéria-prima argilosa. Este índice é obtido por meio da subtração entre o LL e LP. O maior teor de IP da massa cerâmica em relação à argila fundente indica que a primeira suporta maior variação na água de conformação sem mudança do estado plástico.

\section{Características das composições}

De acordo com a Tabela IV, com o incremento de argila fundente incorporada à massa industrial ocorre um aumento de $\mathrm{SiO}_{2}$, além de aumento dos óxidos fundentes, bem como redução de $\mathrm{Al}_{2} \mathrm{O}_{3}$ e da perda ao fogo (PF).

Através do gráfico da Fig. 3, elaborado a partir dos limites de Atterberg, é possível obter um prognóstico da etapa de conformação por extrusão de matérias-primas argilosas. Constata-se que uma incorporação de até $30 \%$ de argila fundente à massa industrial praticamente não alterou seu posicionamento no gráfico. Tanto a massa industrial quanto as composições elaboradas se situam em torno da região de extrusão considerada adequada. Entretanto, estão distantes da região de extrusão considerada ótima. Para alcançar a região de extrusão ótima seria necessário incorporar materiais não plásticos na massa cerâmica. Entretanto, isto pode ocasionar uma redução na resistência mecânica.

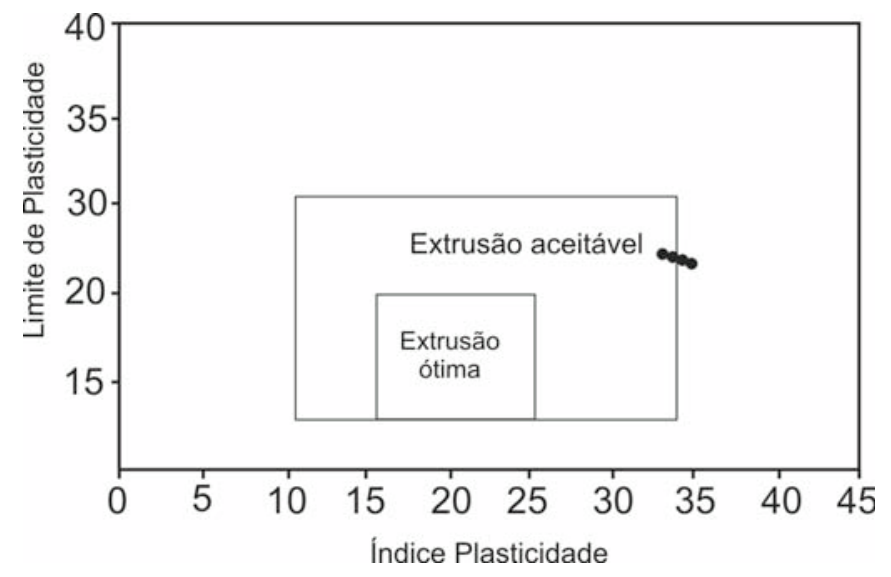

Figura 3: Prognóstico da etapa de conformação através da plasticidade. $(\bullet)$ Localização das composições.

[Figure 3: Prognostic of the extrusion stage through the plasticity. (•) Location of the compositions.]

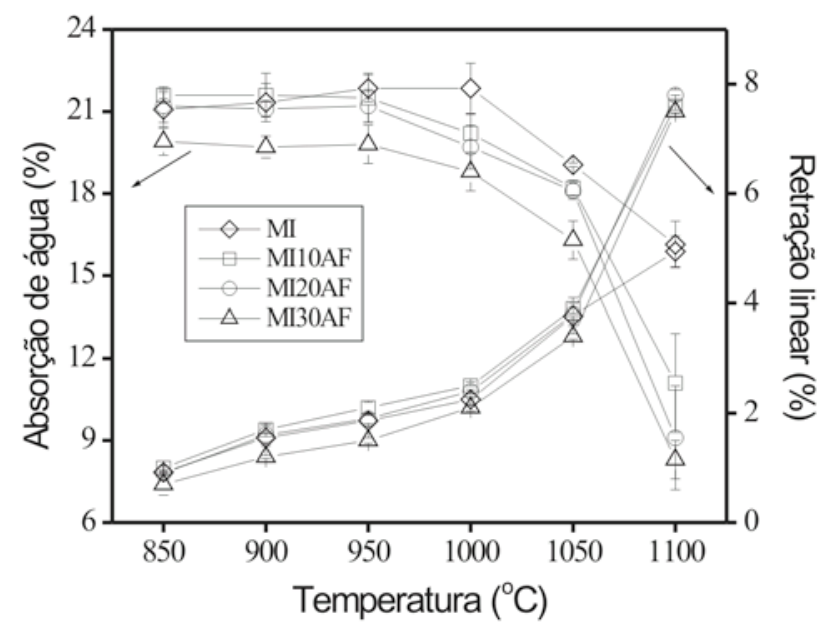

Figura 4: Diagrama de gresificação das composições.

[Figure 4: Gresification diagram of the composition.]

\section{Propriedades tecnológicas}

A Fig. 4 mostra o diagrama de gresificação das composições estudadas. Observa-se que até $20 \%$ de incorporação de argila fundente, praticamente não houve alteração nos valores de absorção de água até a temperatura de $950{ }^{\circ} \mathrm{C}$. A partir desta temperatura, a absorção de água das composições MI10AF e MI20AF apresenta uma sensível redução em relação à massa industrial MI. Já a composição com $30 \%$ de argila fundente MI30AF apresenta uma significativa redução da absorção de água quando comparada com a massa industrial MI em todas as temperaturas de queima. Observa-se também que a incorporação de argila fundente diminuiu em $50{ }^{\circ} \mathrm{C}$ a temperatura de início da redução da absorção de água. Nota-se que praticamente não há alteração da absorção de água da massa industrial MI entre $850^{\circ} \mathrm{C}$ e $1000^{\circ} \mathrm{C}$. Nas composições com incorporação de argila fundente (M10AF, MI20AF e MI30AF) a redução da absorção de água inicia-se a $950{ }^{\circ} \mathrm{C}$. O valor máximo de 
Tabela IV - Composição química das amostras (\% em peso).

[Table IV - Chemical composition of the samples (wt. \%).]

\begin{tabular}{lccccccccc}
\hline \multirow{2}{*}{ Composições } & \multicolumn{1}{l}{ Determinações } \\
\cline { 2 - 9 } & $\mathbf{S i O}_{2}$ & $\mathbf{A l}_{2} \mathbf{O}_{3}$ & $\mathbf{F e}_{2} \mathbf{O}_{3}$ & $\mathbf{T i O}_{2}$ & $\mathbf{C a O}$ & $\mathbf{M g O}$ & $\mathbf{K}_{2} \mathbf{O}$ & $\mathbf{N a}_{2} \mathbf{O}$ & $\mathbf{P F}$ \\
\hline MI & 42,49 & 29,24 & 9,21 & 1,44 & 0,24 & 1,10 & 1,41 & 0,51 & 14,08 \\
\hline MI10AF & 44,98 & 27,83 & 8,87 & 1,36 & 0,26 & 1,14 & 1,63 & 0,52 & 13,17 \\
\hline MI20AF & 47,46 & 26,41 & 8,53 & 1,28 & 0,27 & 1,18 & 1,85 & 0,53 & 12,27 \\
\hline MI30AF & 49,95 & 25,00 & 8,19 & 1,20 & 0,28 & 1,21 & 2,07 & 0,54 & 11,36 \\
\hline
\end{tabular}

Tabela V - Parâmetros de porosidade das composições MI e M30AF obtidos por porosimetria de mercúrio. [Table V-Parameters of porosity of the compositions MI and MI30AF obtained from mercury porosimetry.]

\begin{tabular}{lllllll}
\hline & \multicolumn{5}{c}{ Composições } \\
\cline { 2 - 7 } & \multicolumn{3}{c}{ MI } & \multicolumn{4}{c}{ MI30AF } \\
\cline { 2 - 7 } & $900{ }^{\circ} \mathrm{C}$ & $1000{ }^{\circ} \mathrm{C}$ & $1100{ }^{\circ} \mathrm{C}$ & $900{ }^{\circ} \mathrm{C}$ & $1000{ }^{\circ} \mathrm{C}$ & $1100{ }^{\circ} \mathrm{C}$ \\
\hline Volume de mercúrio intrudido $\times 10^{-2}\left(\mathrm{~cm}^{3} / \mathrm{g}\right)$ & 29,63 & 29,06 & 15,99 & 22,15 & 12,96 & 9,45 \\
\hline Porosidade aparente $(\%)$ & 43,81 & 43,33 & 29,62 & 38,47 & 26,47 & 20,79 \\
\hline Área superficial total $\left(\mathrm{m}^{2} / \mathrm{g}\right)$ & 20,49 & 12,90 & 2,29 & 17,17 & 7,63 & 1,66 \\
\hline Diâmetro médio de poro $\times 10^{-2}(\mu \mathrm{m})$ & 9,84 & 24,72 & 169,30 & 7,88 & 10,19 & 61,30 \\
\hline
\end{tabular}

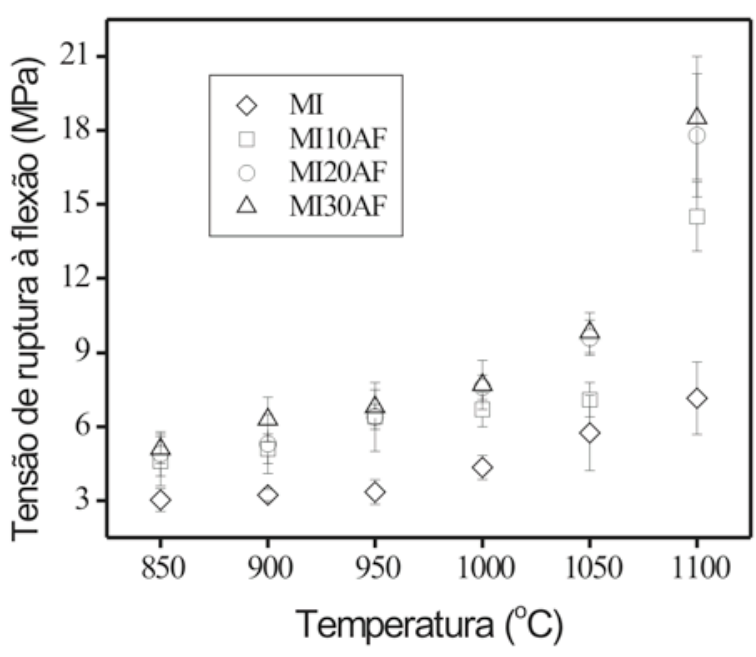

Figura 5: Tensão de ruptura à flexão das composições em função da temperatura de queima.

[Figure 5: Flexural rupture strength of the compositions as a function of the fired temperature.]

absorção de água para telhas do tipo romana, 18\% [17] é alcançado pelas composições estudadas nas seguintes temperaturas: $\mathrm{MI}-1066^{\circ} \mathrm{C}$; MI10AF e MI20AF - $1050^{\circ} \mathrm{C}$; e MI30AF - $1016^{\circ} \mathrm{C}$.

Em relação ao parâmetro de retração linear, observa-se que

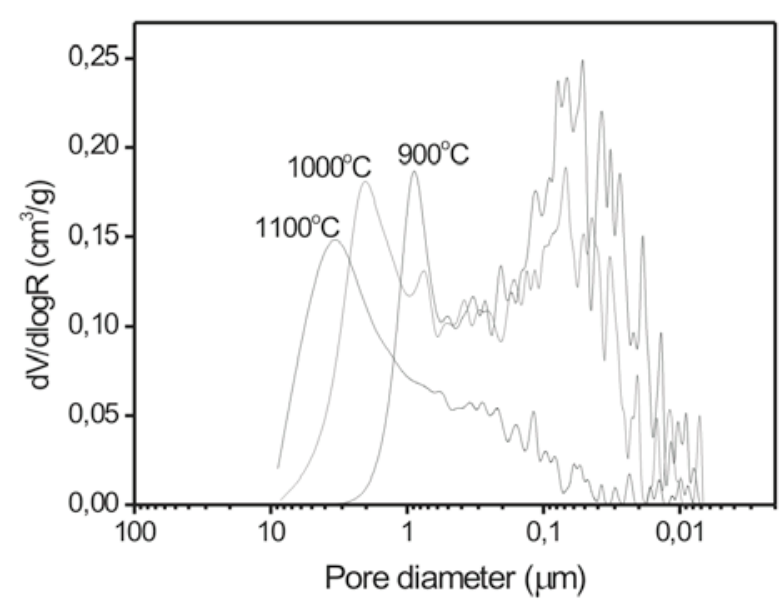

Figura 6: Curvas de distribuição de tamanho de poros da composição MI.

[Figure 6: Pore size distribution curves of the composition MI.]

ocorre um incremento com o aumento da temperatura de queima. Isto decorre em função da densificação do material. Nota-se também que até $1050{ }^{\circ} \mathrm{C}$ praticamente não há mudanças significativas nos valores de retração linear com o incremento de argila fundente. 


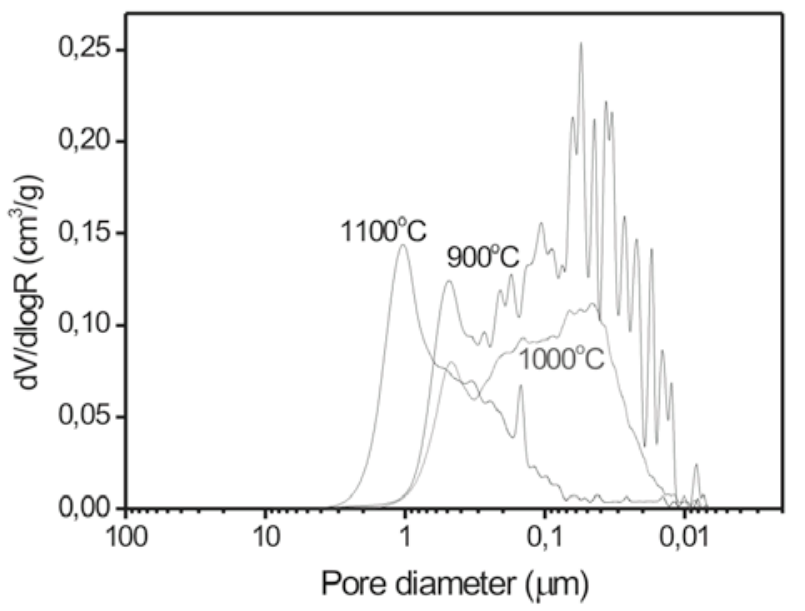

Figura 7: Curvas de distribuição de tamanho de poros da composição MI30AF. [Figure 7: Pore size distribution curves of the composition MI30AF.]
Na Fig. 5 observa-se que ocorre um incremento da tensão de ruptura à flexão para todas as composições com o aumento da temperatura de queima. Este comportamento é bastante conhecido e está associado à redução da porosidade e consolidação estrutural [18]. Observa-se também que o aumento da adição de argila fundente também possbilita um incremento da resistência mecânica.

\section{Microestrutura}

A Tabela $\mathrm{V}$ apresenta dados de porosimetria de mercúrio. O menor volume de mercúrio intrudido com a incorporação de argila fundente indica uma menor porosidade aparente e tem, como conseqüência, menor área superficial específica total e menor diâmetro médio de poro em comparação com a argila pura. Com o incremento da temperatura de queima, observa-se para ambas as massas uma redução tanto da porosidade aparente
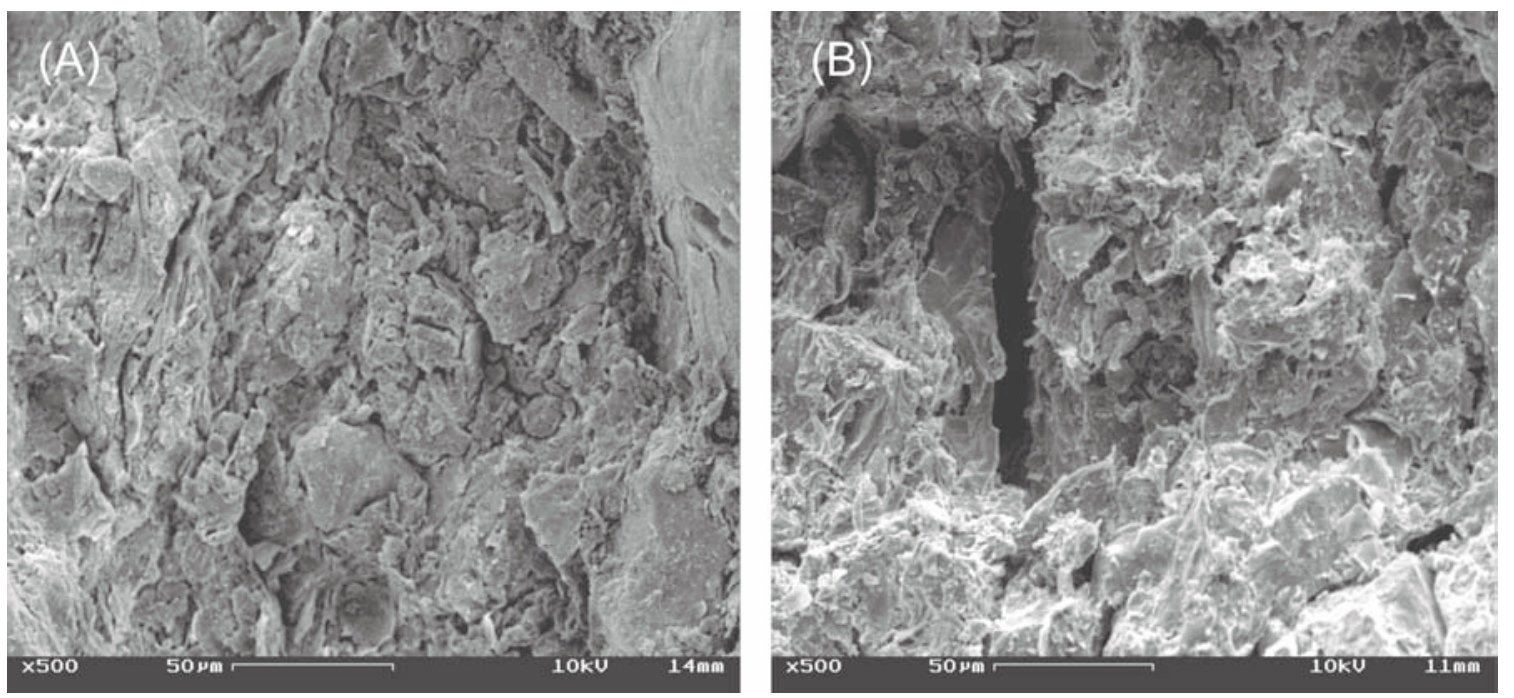

Figura 8: Micrografias de microscopia eletrônica de varredura da superfície de fratura da massa industrial MI. (a) $900{ }^{\circ} \mathrm{C}$; (b) $1100^{\circ} \mathrm{C}$. [Figure 8: SEM micrographs of the fracture surface of the industrial body MI. (a) $900{ }^{\circ} \mathrm{C}$; (b) $1100^{\circ} \mathrm{C}$.]
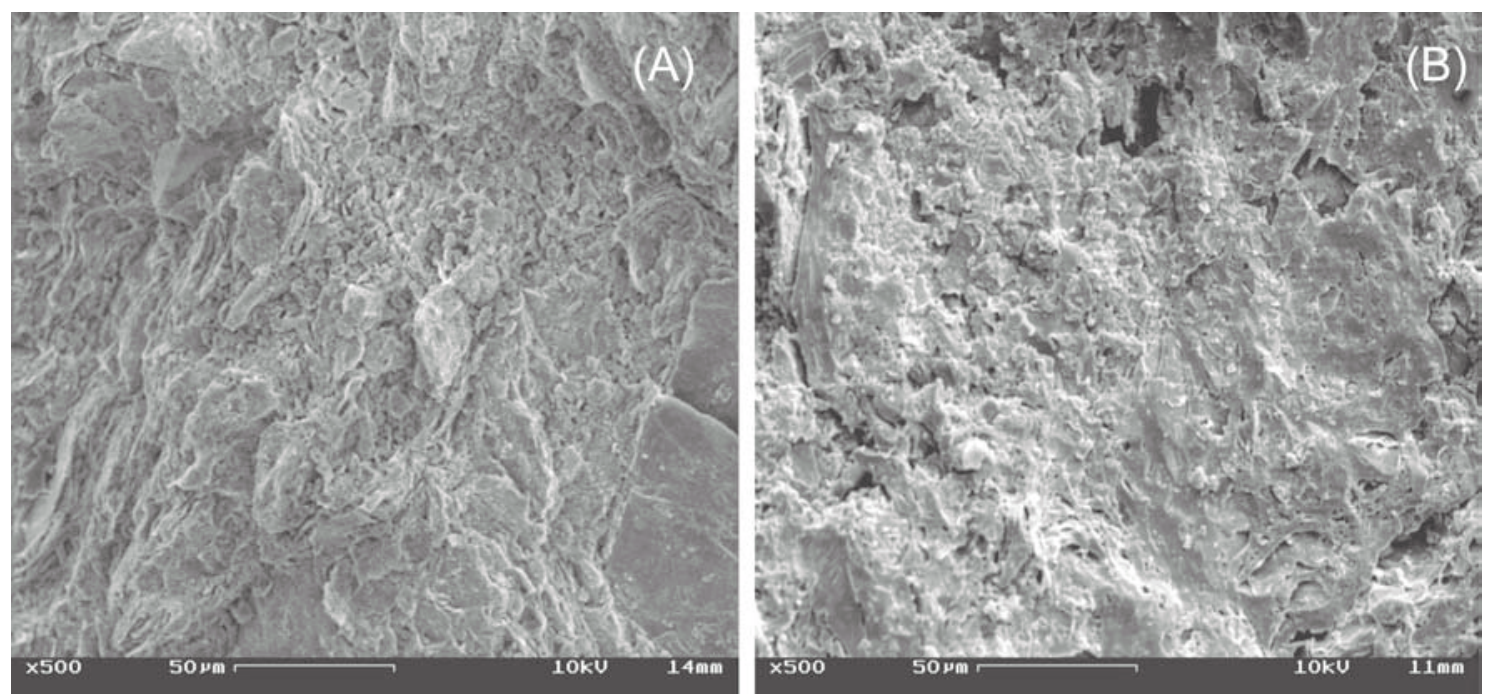

Figura 9: Micrografias de microscopia eletrônica de varredura da superfície de fratura da composição MI30AF. (a) $900{ }^{\circ} \mathrm{C}$; (b) $1100{ }^{\circ} \mathrm{C}$. [Figure 9: SEM micrographs of the fracture surface of the composition MI30AF. (a) $900{ }^{\circ} \mathrm{C}$; (b) $1100^{\circ} \mathrm{C}$.] 
quanto da área superficial total e aumento do diâmetro médio de poro.

As Figs. 5 e 6 apresentam as curvas de distribuição de tamanho de poros das composições MI e MI30AF queimadas a $900{ }^{\circ} \mathrm{C}, 1000{ }^{\circ} \mathrm{C}$ e $1100{ }^{\circ} \mathrm{C}$. A porosidade pode ser melhor avaliada dividindo-as em dois tipos de tamanho de poros: $<1 \mu \mathrm{m}$ e $>1 \mu \mathrm{m}$. Pode-se observar que ambas as composições apresentam, nas temperaturas de $900{ }^{\circ} \mathrm{C}$ e $1000{ }^{\circ} \mathrm{C}$, uma predominância de poros tamanho $<1 \mu \mathrm{m}$. Com o aumento da temperatura ocorre um deslocamento nas curvas em direção ao maior tamanho de poros. Este comportamento está associado à sinterização das peças, o que preferencialmente fecha os poros de pequeno diâmetro, acarretando um aumento de tamanho dos poros maiores. Isto é ainda mais significativo a $1100^{\circ} \mathrm{C}$.

Para ilustrar o efeito da temperatura e da adição de argila fundente são mostradas as superfícies de fratura da massa industrial MI, Fig. 8, e da composição MI30AF, Fig. 9, queimadas: (a) $900{ }^{\circ} \mathrm{C}$ e (b) $1100{ }^{\circ} \mathrm{C}$. Observa-se na Fig. 8a que a massa industrial $\mathrm{MI}$ apresenta a $900{ }^{\circ} \mathrm{C}$ uma superfície de fratura bastante grosseira. Nesta superfície são observados defeitos como vazios, trincas e pequenos poros. Pode-se observar também regiões em que parece ter ocorrido desprendimento de material. Estes defeitos estão associados a uma microestrutura que mostra claramente um baixo grau de sinterização. Já a composição com $30 \%$ de argila fundente, MI30AF, queimada a $900^{\circ} \mathrm{C}$, Fig. 9a, apresenta uma superfície menos grosseira e sem tantos defeitos quando comparada com a da massa industrial MI. Este resultado é conseqüência da incorporação de argila ilítica que, além de contribuir para tornar mais efetivo o processo de sinterização por fase líquida [19], reduz a perda de massa durante a queima. É possível observar também que o aumento da temperatura de queima exerceu uma forte influência na microestrutura das composições estudadas. Ainda que a massa industrial MI, Fig. 8b e a composição MI30AF, Fig. $9 \mathrm{~b}$ apresentem defeitos na temperatura de $1100^{\circ} \mathrm{C}$, suas microestruturas são mais compactas. Este comportamento está relacionado com a significativa influência que a temperatura exerce para melhorar a consolidação microestrutural das partículas, através do aumento da quantidade de fase líquida e redução de sua viscosidade.

A incorporação de argila fundente pode ser uma alternativa para a melhoria da qualidade das telhas produzidas em Campos dos Goytacazes. A longa distância entre o pólo cerâmico de Santa Gertrudes e o município de Campos dos Goytacazes é um fator que pode inviabilizar economicamente esta alternativa. Uma análise superficial indica que a incorporação de $30 \%$ de argila fundente na massa cerâmica aumenta em cerca de $10 \%$ o custo de fabricação. Desta forma, deve ser realizada uma investigação mais apurada sobre eventuais depósitos de argilas fundentes no Estado do Rio de Janeiro visando um possível aproveitamento para fabricação de cerâmica vermelha de elevado valor agregado.

\section{CONCLUSÕES}

Neste trabalho de investigação da influência da adição de uma argila fundente ilítica em massa para telhas de predominância caulinítica, as seguintes conclusões foram obtidas:

- Existem significativas diferenças entre a argila fundente e a massa de cerâmica vermelha caulinítica de Campos. Enquanto a argila fundente é caracterizada por apresentar elevado teor de óxidos alcalinos, provenientes do argilomineral ilita e dos feldspatos, a massa industrial caulinítica é caracterizada por apresentar baixo percentual de óxidos alcalinos, elevado teor de alumina e elevada perda ao fogo.

- Com o incremento de argila fundente incorporada à massa cerâmica, ocorreu uma sensível melhora nas propriedades de queima avaliadas: A absorção de água foi reduzida, enquanto que a tensão de ruptura à flexão aumentou. Isto é tanto mais significativo quanto mais elevada for a temperatura.

- Nas temperaturas de $950{ }^{\circ} \mathrm{C}$ e $1000{ }^{\circ} \mathrm{C}$, que corresponde à faixa de maiores temperaturas utilizadas por indústrias de Campos para fabricação de telhas, a incorporação de $30 \%$ de argila fundente contribuiu para uma sensível redução da absorção de água da massa industrial. Entretanto, o valor máximo de absorção de água aceitável para telhas do tipo romana, $18 \%$, só foi alcançado na temperatura de $1016^{\circ} \mathrm{C}$. Já a massa industrial alcançou o valor de $18 \%$ de absorção de água somente a $1066{ }^{\circ} \mathrm{C}$.

- A incorporação de argila fundente na composição de massa industrial além de não alterar os parâmetros de extrusão, poderia contribuir para a melhoria da qualidade das telhas cerâmicas produzidas no município de Campos dos Goytacazes.

\section{AGRADECIMENTOS}

Os autores agradecem ao $\mathrm{CNPq}$ pelo apoio para realização deste trabalho, Proc. 150444/2003-6, e à empresa Calcáreo Cruzeiro pelo fornecimento da argila fundente.

\section{REFERÊNCIAS}

[1] C. M. F. Vieira, T. M. Soares, S. N. Monteiro, Cerâmica 49, 312 (2003) 245.

[2] C. M. F. Vieira, J. Alexandre, e S. N. Monteiro, Actas del Congreso CONAMET/SAM-SIMPOSIO MATERIA 2002, Santiago (2002) p. 673.

[3] C. M. F. Vieira, S. N. Monteiro, Tile \& Brick Int. 18, 3 (2002) 152. [4] H. G. Riella, E. U. de C. Franjndlich, M. Durazzo, Cerâmica Industrial 7, 3 (2002) 33.

[5] M. G. Fonseca, G. R. de Paula, R. A. Teixeira, F. G. Melchiades, A. O. Boschi, Anais do $43^{\circ}$ Congresso Brasileiro de Cerâmica, Florianópolis, SC (1999) cdrom, ref. 2-443.

[6] G. P. Emiliani, F. Corbara, Tecnología Cerámica - La Lavorazione, vol. 1, Gruppo Editoriale Faenza Editrice, Faenza (1999) p. 97.

[7] C. M. F. Vieira, B. R. Cardoso, S. N. Monteiro, Cerâmica Informação 25 (2002) 38.

[8] C. M. F. Vieira, T. M. Soares, S. N. Monteiro, C. C. Peiter, J. Duailibi Filho, Anais do $47^{\circ}$ Congresso Brasileiro de Cerâmica, J. Pessoa, PB (2003) cdrom, ref. 5-36.

[9] C. R. de Oliveira, J. Castral Jr, C. V. dos Santos, C. Bolfarini, L. C. Chiari, Anais do $44^{\circ}$ Congresso Brasileiro de Cerâmica, 
S. Pedro, SP (2000) cdrom, ref. 5- 190.

[10]C. V. dos Santos, A. A. P. Chagas, J. Castral Jr, Anais do $43^{\circ}$ Congresso Brasileiro de Cerâmica, Florianópolis, SC (1999) cdrom, ref. 5-77.

[11] ABNT - Associação Brasileira de Normas Técnicas, Determinação do Limite de Plasticidade, NBR - 7180, Rio de Janeiro (1984).

[12] ABNT - Associação Brasileira de Normas Técnicas, Determinação do Limite de Liquidez, NBR - 6459, Rio de Janeiro (1984).

[13] ASTM - American Society for Testing and Materials, Flexural Properties of Ceramic Whiteware Materials, C 674-77 (1977).

[14] ASTM - American Society for Testing and Materials, Water Absorption, Bulk Density, Apparent Porosity, and
Apparent Specific Gravity of Fired Whiteware Products, C 373-72 (1972).

[15] A. Barba, V. Beltrán, C. Feliu, J. García, F. Ginés, E. Sánchez, V. Sanz, Matérias primas para la Fabricación de Soportes de Baldosas Cerámicas, Instituto de Tecnologia Cerámica, Castellón (1997) p. 223.

[16] M. P. Abajo, Manual Sobre Fabricación de Baldosas Tejas y Ladrillos, Beralmar, S. A., Terrassa (2000) p. 129.

[17] ABNT - Associação Brasileira de Normas Técnicas, Telha cerâmica tipo romana - especificação, NBR - 13582, Rio de Janeiro (1996).

[18] Y. Kobayashi, O. Ohira, Y. Ohashi, E. Kato, J. Am. Ceram. Soc. 75, 7 (1992) 1801.

[19] J. E. E. Navarro, A. Albaro, Técnica Cerâmica, 91 (1981) 119. (Rec. 28/04/04, Ac. 07/05/04) 